\title{
Technologic organization of malaria control in São Paulo, Brazil, 1930-19901
}

\author{
Rita Barradas Barata ${ }^{2}$
}

ABSTRACT Since the 1970s, when the world seemed on the threshold of malaria eradication, the incidence of the disease has increased in several countries. The upturn in cases raised a series of questions, and for some time malariologists and public health authorities scarcely understood what was happening. In an attempt to better comprehend the process, this article reviews the frequency of malaria cases in São Paulo, Brazil, between 1930 and 1990, examining the following factors in each of three 20-year time periods: the importance of malaria in the society, the conditions under which the disease occurred, the epidemiologic knowledge of the time, the technical instruments available to fight it, and the control strategies that were used. Through the construction of technological models based on these factors, it became clear that the occurrence of the disease, knowledge about it, and, consequently, the ways it was dealt with changed over time. In light of this research, the article discusses current options for the control of malaria.

The purpose of the research reported here was two-fold: first, to examine why the incidence of malaria increased in various regions of the world in the 1980s, precisely at a time when hopes for eradicating this disease were highest; and second, to seek an explanation by applying a theoretical model capable of articulating epidemiologic knowledge, social needs,

\footnotetext{
1 This article was published in Spanish in this journal (Vol. 1, No. 5, 1997, pp. 335-343) under the title "Organización tecnológica del control de la malaria en São Paulo, Brasil, de 1930 a 1990." The research reported here was sponsored by the Program of Small Grants for Investigation of the Social and Economic Aspects of Tropical Diseases of the Social Sciences Laboratory, Central University of Venezuela, with financial support provided by the World Bank/WHO Special Program for Research and Training in Tropical Diseases.

2 Department of Social Medicine, Facultad de Ciências Médicas da Santa Casa de São Paulo, São Paulo, Brazil. Mailing address: Rua Cesário Motta, Jr. $616^{\circ}$ andar, São Paulo, SP, Brazil cep 01221-020. Fax: (055) (011) 222-0432.
}

and the practices adopted to satisfy those needs.

Initially, reasons suggested to explain the increased incidence focused on problems directly related to the way eradication campaigns were conducted. Failure of the campaign-based strategy was attributed to a wide range of things, including difficulties of a technical, operational, administrative, financial, and political nature. However, more detailed analysis linking various factors (the presence of the disease, its social repercussions, current epidemiologic concepts, and the control measures adopted) within a single theoretical framework pointed up new issues requiring different explanations.

The central purpose of our research has been to assess, through various historical periods, how malaria became a health problem of a social nature that evoked certain institutional control practices, and to determine how much the epidemiologic knowledge available in each period has served to guide the planning of interventions.

The selection of São Paulo as the state for this study was based on practical considerations, such as ease of access to information, as well as theoretical considerations, such as the fact that the organizations engaged in malaria control activities in São Paulo are the oldest currently in operation in Brazil and that the eradication campaign has not been beset by economic, administrative, operational, or political difficulties.

\section{MATERIALS AND METHODS}

The research, based on document analysis, took the following method- 
ologic steps: selection of study materials from the universe of available documents (some 1500 books, articles, reports, technical guidelines, etc.); reading and indexing of the nearly 800 selected documents; chronologic classification of the documents by period; organization of the information under four subject headings (epidemiologic status of malaria, notions about malaria's epidemiology, available control methods, and institutional organization of intervention practices); development of data and identification of key concepts for each time period and subject heading; development (for each time period) of technologic models integrating social needs to combat malaria with epidemiologic knowledge of the disease and current intervention practices. In discussing each model, an attempt has been made to highlight its most important features.

The specific universe of documents reviewed included, among others, the following: reports of the Malaria Prophylaxis Inspectorate (1923-1932), Malaria Prophylaxis Service (19331958), Malaria Eradication and Chagas' Disease Prophylaxis Service (1959-1969), Superintendency of Environmental Sanitation (1970-1974), and Superintendency for Control of Endemic Diseases (1975-1994); article reprints, training manuals, service records, advertising materials, reports of national and international meetings, work program documents, and works in the collections and archives of the Geraldo Buralli Library of the Superintendency for Control of Endemic Diseases (SUCEN) dealing with the period 1900-1994; the Revista Brasileira de Malariologia e Doenças Tropicais (1949-1986); the Revista da Fundação Serviços Especiais de Saúde Pública (1947-1985); reports of the WHO Committee of Experts on Malaria (19471986); reports of the National Malaria Service and the Meetings of Directors of National Malaria Eradication Services on file in the SUCEN Library; two reports, one entitled Estado de la erradicación de la malaria en las Américas, published by $\mathrm{PAHO}$ beginning in 1962, and the other entitled Case studies in epidemiology of malaria, published by
WHO beginning in 1971; the Quarterly Bibliography of Major Tropical Diseases, published by WHO beginning in 1980 ; and textbooks on malaria by wellknown authors published in the twentieth century and available in the SUCEN Library or the personal library donated by Dr. Firmino de Oliveira to the Department of Social Medicine of the Medical School of Santa Casa de São Paulo.

\section{ENVIRONMENTAL-ECOLOGIC MODEL, 1930-1950}

In São Paulo State, the 1930-1950 period witnessed a transition from a predominantly agrarian and exportoriented economy to an industrial economy. It was a time of major changes occurring throughout the entire state. In the areas where the earliest settlement had taken place (from 1532 to 1886), subdivision of large rural properties accelerated; cultivation of a variety of products for domestic consumption replaced production for export; and creation of industries was encouraged. In the areas settled from 1880 to 1920, agricultural production diversifiedaccompanied by a large migratory influx from other parts of Brazil and abroad. Finally, the areas most recently settled continued to pursue production for export, based primarily on cotton and coffee; these areas experienced the highest migration rates in the entire state.

Overall, the state's population was predominantly rural, with most of the economically active population engaged in agricultural activities. There existed, therefore, a series of factors favoring malaria: a sizable rural population; settlement and development of new areas; large migratory movements; and construction of infrastructure facilities such as hydroelectric plants and highways $(1,2)$.

For the rural worker of 1930-1950, having malaria meant critically limiting his ability to earn a living (because he could not appropriately perform his daily tasks). For society, malaria meant reduced labor capacity and a consequent loss of productivity and production volume. Accordingly, infection of a relatively large number of rural workers had major consequences; and so malaria was recognized as an obstacle to the development process and prompted creation of institutions designed to combat it. During this period, recorded malaria incidences were high, generally exceeding 200 cases per 100000 inhabitants except in the initial years, when few diagnostic centers were operating in the state (Table 1).

Distribution of cases within the state still reflected the various stages of settlement, indicating that malaria's appearance was basically the result of living conditions. In the oldest areas the malaria incidence was low or nonexistent, except along the coast, where the incidence was higher as a result of the vector's high density. The prevailing patterns of land use for agricultural or development purposes, the stability of population groups, and urban and industrial growth had combined to create conditions unfavorable for appearance of the disease, and in these areas malaria cases tended to be sporadic. In those parts of the transition area where small properties or farms with few workers predominated, the malaria incidence also tended to be low. However, malaria rates tended to be high in parts of the transition area and in recently settled areas where properties were large and where the prevailing land ownership system attracted large numbers of immigrants. In addition, epidemics were more frequent in the recently settled areas as a result of timber cutting and ongoing migration (3).

With regard to public health concepts about malaria, a health-disease concept that could be called ecologicenvironmental prevailed, one that accorded a central role to the environment. The main idea was that malaria's occurrence depended upon the interaction of three groups of factorsetiologic, vector-related, and hostrelated-all mediated by the environment. In malarious areas, the environment provided a number of conditions needed for the survival of 
TABLE 1. Annual recorded malaria incidences per 100000 inhabitants in the State of São Paulo, Brazil, 1933-1950

\begin{tabular}{rrrrrr}
\hline Year & Rate & Year & Rate & Year & Rate \\
\hline 1933 & 52 & 1939 & 337 & 1945 & 690 \\
1934 & 79 & 1940 & 714 & 1946 & 318 \\
1935 & 477 & 1941 & 2423 & 1947 & 282 \\
1936 & 143 & 1942 & 285 & 1948 & 88 \\
1937 & 212 & 1943 & 268 & 1949 & 86 \\
1938 & 224 & 1944 & 236 & 1950 & 261 \\
\hline
\end{tabular}

Source: Population data were obtained from the Brazilian Geographic and Statistical Institute.

a Case data for the period 1933-1938 were provided by the Malaria Prophylaxis Inspectorate, while those for the period 1939-1950 were provided by the Malaria Prophylaxis Service.

plasmodia, anopheline species, and human beings; that favored contact among them; and that permitted consolidation of a so-called "reservoir mechanism" by which the transmission cycle became established. In this model the environment took the place of social structure and permitted what was termed "naturalization" of the health-disease process. The variables studied were examined as an unstructured set of factors related in a linear, paired, or sequential manner. Hence the emphasis given here to the "ecologic-environmental" designation.

During this period entomologic studies intensified and criteria were established for evaluating the diseasetransmitting capacity of each vector species. It was observed increasingly that disease distribution was linked to vector distribution. In São Paulo State the primary malaria vectors were found to be Anopheles (N.) darlingi in the highlands; $A$. (N.) tarsimaculatus, $A$. (K.) cruzi, and $A$. (K.) bellator in the coastal region; $A$. (N.) strodei in the specific municipality of Marilia; and A. (N.) albitarsis exclusively in the coastal towns of Iguape and Cananéia (4-9).

Vector control interventions during the period were limited to controlling the larvae by means of small engineering works designed to reduce the number of anopheline breeding sites. Despite the fact that these measures were aimed at modifying the environment, their effect was relatively minor, as a scarcity of financial resources prevented them from being extensive enough to significantly modify vector density. Inspection teams frequently traveled back and forth between prefectures to visit landowners in an attempt to persuade them to finance and implement such works; but the teams themselves only went so far as to provide technical guidance.

As knowledge of the vectors grew, vector control efforts centered on socalled "focal monitoring"-which involved identifying and counting breeding sites, studying and identifying larvae of species playing a role in transmission, applying treatments of petroleum or Paris green solution, and providing follow-up. The felt need to carry out this full routine, combined with the vast number of wet areas in the state, added to the difficulties of identifying $A$. (N.) darlingi breeding sites and greatly limited the application of this strategy $(10,11)$.

The existence of technical knowledge and intervention strategies was no guarantee that these would be put into practice; and indeed, peculiarities of São Paulo's social organization tended to prevent this from happening. Specifically, the same social organization that discouraged ample expression of public health needs and reduced such expression to matters affecting the work force also limited the application of technical knowledge, distribution of which was inevitably unequal. The principal purpose of malaria control activities in São Paulo during this period was to keep the work force employed in agricultural activities and construction of infrastructure. Given the financial limitations cited above, priority areas for transmission control activities were infrastructure works, agroindustrial enterprises, and the economically very active urban areas.

During 1930-1950, malaria was commonplace throughout virtually the entire state. High incidence rates and epidemics were observed at fiveyear intervals, with transmission being predominantly rural. The ecologicenvironmental concept (the belief that numerous unranked factors, fragmented and linearly correlated, determined the appearance of the disease) was prevalent. Chief among such factors were ones linked to the physical environment, since these directly affected vector survival and proliferation. The epidemiologic survey emerged as the primary instrument for diagnosing current malaria status, and control efforts were based on the idea that malaria was a local problem, i.e., a disease with a collective scope that was expressed in a particular area as a function of local characteristics. Control activities sought to reduce vector populations by eliminating or treating breeding sites, with a view to lessening mosquito density.

As time passed, it was necessary to adjust the intervention strategy to the needs of control activities, which needed to be extended to the entire population and adapted to the socioeconomic characteristics of São Paulo society. To accomplish this, priorities were established. Nevertheless, despite these initiatives directed at organizing and extending control activities, at the end of the 1940s malaria remained a significant public health problem in the state.

At the end of World War II, WHO created a group known as the Committee of Experts on Malaria, which in 1947 set forth the principal guidelines for controlling the disease. Its first report, published in 1947, highlighted technical advances and emphasized use of new synthetic drugs, such as chloroquine, and of larvicides with residual action. Its second report, published in 1948, proposed creation of national agencies for controlling "and even eradicating" malaria. It was at this point that a new phase of worldwide control activities began $(12,13)$. 


\section{THE CAMPAIGN-BASED TECHNICAL MODEL, 1950-1970}

In the early 1950 s, scarcely $18 \%$ of the state's original vegetative coverage remained. São Paulo had become the principal producer of nine of the country's most important agricultural products, even though as early as 1950 its urban population had surpassed its rural population. This transformation of the state's urban-rural demographic profile was the result of two independent trends: increased employment in the industrial sector, which was favored by an influx of foreign capital following modification of the profit remittance law; and intensification of the agricultural mechanization process, accompanied by dissolution of the settlement system and transformation of settlers into itinerant or "floating" workers who would leave the fields to settle in the outlying areas of urban centers $(1,14,15)$.

In the 1960s, these transformations intensified, resulting in both an absolute and relative reduction of the rural population, even in areas where agricultural work continued to predominate. By the end of the decade, the urban population had become $80 \%$ of the total population, and it was possible to observe a pronounced demographic concentration in the state's industrial poles.

These new conditions characterizing economic and social organization also served to alter malaria's prevalence. Following an initial deforestation and settlement phase, during which the malaria incidence tended to be high, there came an agricultural consolidation phase in which the malaria incidence tended to decline. This latter tendency was reinforced by reduction of the number of rural workers and by environmental modifications produced by the industrialization and urbanization processes-including pollution of rivers with industrial discharges and creation of sewage collection networks-which had the effect of modifying many breeding sites of A. $(\mathrm{N})$ darlingi $(16,17)$.

During the 1950s, the malaria incidence tended to average over 30 cases per 100000 inhabitants (Table 2). These rates dropped sharply in the 1960s as a result of eradication efforts, though what appeared to be the usual epidemic flare-up of autochthonous cases on a five-year cycle occurred in 1956. Also, the unequal distribution of cases within the state persisted, with the concentration and incidence of autochthonous cases being greater in the newly settled area, principally along the border with Matto Grosso state.

In these years the economic implications of malaria among rural workers took on new meaning. For the itinerant laborer, the disease still meant fewer days of work and, accordingly, lower income, while for the "rural producer" the disease no longer had the same importance. However, worker health needs could be expressed collectively, and definition of these collective needs was being provided by the State, as part of a development policy that assumed modernization of agricultural production. The malarious rural worker symbolized the danger that transmission would be introduced into urban areas, thereby placing industrial workers at risk. This realization sharpened the impetus to press forward with commitments previously made by the federal government and international organizations, such as $\mathrm{PAHO}$, with regard to implementation of an eradication program.

The introduction of chloroquine and the pesticide dichlorodiphenyltri- chloroethane (DDT) as control vehicles beginning in 1947 signified that, in practice, malaria was deemed to be a disease of the masses; and that made it possible to expand the intervention in previously inconceivable ways. The ease with which chloroquine could be administered and the result that could be achieved with a single chloroquine treatment made large-scale distribution and administration by unskilled individuals feasible. Intradomiciliary sprayings with long-active and residually effective DDT provided a simple and relatively cheap way to combat vectors. Together, these new instruments gave malariologists hope of being able to noticeably reduce malaria transmission, or even interrupt it altogether, in areas where it was endemic.

Initial controversy about whether the most appropriate approach was to seek eradication of the vector or the disease began to be resolved following failure of an attempt to eradicate A. labranchiae in Sardinia. Although efforts to eradicate the vector on the island were unsuccessful, they demonstrated the feasibility of interrupting transmission and thereby eradicating the disease (18).

The insistence of international agencies on malaria eradication did not produce immediate effects in the countries, because it ran up against the skepticism of many malariologists; and the significant reductions in incidence

TABLE 2. Annual recorded malaria incidences and autochthonous case rates per 100000 inhabitants in the State of São Paulo, Brazil, 1951-1970a

\begin{tabular}{lccccc}
\hline Year & $\begin{array}{c}\text { Total } \\
\text { incidence }\end{array}$ & $\begin{array}{c}\text { Autochthonous } \\
\text { case rate }\end{array}$ & Year & $\begin{array}{c}\text { Total } \\
\text { incidence }\end{array}$ & $\begin{array}{c}\text { Autochthonous } \\
\text { case rate }\end{array}$ \\
\hline 1951 & 80 & 17 & 1961 & 59 & 37 \\
1952 & 45 & 8 & 1962 & 28 & 12 \\
1953 & 29 & 8 & 1963 & 16 & 1 \\
1954 & 51 & 16 & 1964 & 13 & 1 \\
1955 & 49 & 17 & 1965 & 10 & 2 \\
1956 & 29 & 10 & 1966 & 11 & 2 \\
1957 & 37 & 14 & 1967 & 8 & 1 \\
1958 & 32 & 28 & 1968 & 6 & 1 \\
1959 & 31 & - & 1969 & 5 & 0.2 \\
1960 & 87 & 59 & 1970 & 4 & \\
\hline
\end{tabular}

Source: Population data were obtained from the Brazilian Geographic and Statistical Institute.

${ }^{\text {a }}$ Case data for the period 1951-1958 were provided by the Malaria Prophylaxis Service, while those for the period 1959-1970 were provided by the Malaria Eradication and Chagas' Disease Prophylaxis Services. 
control programs achieved through the use of DDT made the effort required by eradication activities unnecessary. However, emergence of anopheline resistance to residual insecticides, which was observed in several countries, completely changed the picture. Resistance presented the risk of overwhelming the best control instrument yet created, and thus jeopardized both the achievements already recorded and continuation of activities.

The resulting worldwide eradication campaign, an undertaking directed at coping with the imminent risk of widespread resistance, was conceived as an operation to be carried out in four phases. The first, a one-year preparatory phase, included a preliminary survey defining the area affected by malaria and planning and organization of appropriate measures. The second, called the attack phase, was to last between two and three years and was to entail spraying of all rural households in the malarious area with DDT in periodic cycles until transmission was interrupted. The third, designated the consolidation phase, would undertake active search for and radical treatment of all suspect cases as well as elimination of residual transmission foci. Finally, the fourth phase, termed the maintenance phase, was directed at implementing an epidemiologic surveillance system whose purpose would be to prevent reactivation of transmission (19).

As this strategy evolved and was adopted, the ecologic-environmental concept was abandoned and replaced with a series of "technical principles" that would serve to guide malaria control activities. The doctrine of eradication was based on three premises: that the nature of the infection was selflimiting; that the nature of transmission was exclusively intradomiciliary; and that such transmission could be interrupted by reducing the number of infected adult mosquitoes. These circumstances, which generally existed in all parts of the world except Africa, made it possible to apply a common strategy. No further thought was given to the notion of a complex disease whose determining factors varied from one place to another and that manifested itself in different ways under different circumstances. Instead, malaria at that time was evaluated in terms of positive slides and infected vectors.

The eradication campaign was launched in São Paulo State in 1959. The effort involved 198 municipalities, the entire malaria-infested region, making up almost $40 \%$ of the state's total area and containing close to 2.7 million inhabitants ( $23 \%$ of the state's population). The attack phase, carried out from 1960 to 1963, entailed spraying $98 \%$ of the households in the malarious zone on a semiannual cycle. Daily spraying was carefully programmed, standardized, and supervised. An active search was made for individuals with fever, and this led to annual microscopic parasitologic testing of $10 \%$ of the population. Five thousand reporting posts were created for passive search and treatment of suspect cases. The key words were "timeliness," "sufficiency," and "regularity." Each action had to be adapted to the availability of resources and implemented on a timely basis in order to ensure continuity and progress toward achievement of the established goal.

In 1968, upon completion of the first official program evaluation, it was found that the malaria-free zone included $68 \%$ of the population; the consolidation area included $31 \%$ of the population and $53 \%$ of the state's area; and the attack zone had been reduced to 16 municipalities including only $1 \%$ of the population and $3 \%$ of the state's area.

As an action strategy, the eradication campaign took advantage of available technical instruments and conducted interventions as effectively as possible. Standardization helped a relatively small number of specialized professionals extend campaign activities to all necessary sites. A strongly hierarchic structure, in which the tasks assigned to each worker were carefully defined and explained in instruction manuals, together with a detailed and permanent record-keeping system and ongoing supervision, promoted rational use of human resources, materials, and funds-thus maximizing and leveraging their effects. This campaign strategy, with its normative apparatus, afforded an opportunity to extend control activities to all citizens indiscriminately, in order to radically modify the conditions where the disease occurred by means of a territorywide technical intervention that was planned and implemented rigorously and was also relatively short. This represented a considerable improvement over the limitations of the preceding model.

Once the campaign was launched, reduction of the malaria incidence was steady. During the attack phase alone the case incidence fell by $78 \%$ and autochthonous cases (reduced by $98 \%$ ) practically disappeared. The index of positive slides dropped to $0.2 \%$ (a 19fold reduction), and the annual parasite index fell to 0.03 positive slides per 1000 inhabitants. Overall, the results of the campaign were very good; nevertheless, as anticipated, complete interruption of malaria transmission took four years to achieve.

Comparison of malaria incidences recorded in the 1947-1958 period (preceding the campaign) to those recorded after it was launched makes it apparent that the campaign-based strategy with its technologically wellorganized efforts had a major impact on the frequency of the disease. Virtually the same technical intervention instruments were used before and during the campaign: DDT spraying and chloroquine treatment. But it was not until the campaign began that control activities were extensive enough to radically modify the presence of malaria in São Paulo.

\section{FOCAL AND PREVENTIVE MODEL, 1970-1990}

The socioeconomic and demographic transformations experienced by São Paulo State (which had begun in the 1950s), together with the eradication campaign's impact, drastically modified malaria epidemiology. Mechanization of agriculture was even 
more marked in this period than in the preceding period, and seasonal work took on a dominant role as a result of worker migration from neighboring states, especially during harvests. The rural population, which in 1970 accounted for $11.4 \%$ of the total, dropped to scarcely 5\% in 1991 (1).

Few autochthonous malaria cases were detected in this period-less than 100 per year-and many of those that were detected appeared to be imported cases resulting from transmission outside the state. Malaria ceased to be an ongoing problem for the population of São Paulo, becoming instead a latent problem whose appearance was contingent on the epidemiologic situation prevailing in other parts of the country (Table 3).

Despite various difficulties involved with the eradication campaign, when this campaign was applied to the rest of the country it likewise had a marked impact. Before the campaign, new cases were estimated at close to five million per year; but in 1974, after all areas had gone through the attack phase, only 50000 cases were recorded.

However, occupation of the Amazon territory led to a notable increase in transmission during the second half of the 1970s and throughout the following decade (20-22). The effect of these changes in the Amazon would be felt in all areas where transmission of the disease had been interrupted, including São Paulo State. The steady and ever-increasing flow of people between the endemic area and transmission-free areas created a need for epidemiologic surveillance systems permitting timely identification and control of epidemic outbreaks caused by introduction of infected malaria carriers into areas containing vectors and a susceptible population.

Overall, during the 1970s the malaria incidence in São Paulo remained around five cases per 100000 inhabitants, subsequently exhibiting a gradual increase from 1983 to 1987 before declining again by 1990 . Of all the cases recorded in 1983, 98\% were imported from endemic areas, particularly from Rondônia (Pôrto Velho and Ariquemes), Mato Grosso (Colíder and Alta Floresta), and Pará (Itaituba, Marabá, and Concepción de Araguaia). The individuals affected were farm workers, miners, and truckers who would frequently travel back and forth between the endemic area and São Paulo State. Malaria epidemiology within the state during this period was characterized by persistence of transmission in malaria-infested areas of the coast, sporadic reintroduction of cases in the highlands, and increasing numbers of imported cases. Beginning in 1987, the numbers of cases detected in users of injected drugs began to rise $(23,24)$.

By the end of this period malaria had become a problem of a focal

TABLE 3. Annual recorded malaria incidences and autochthonous case rates per 100000 inhabitants in the State of São Paulo, Brazil, 1971-1990a

\begin{tabular}{cccccc}
\hline Year & $\begin{array}{c}\text { Total } \\
\text { incidence }\end{array}$ & $\begin{array}{c}\text { Autochthonous } \\
\text { case rate }\end{array}$ & Year & $\begin{array}{c}\text { Total } \\
\text { incidence }\end{array}$ & $\begin{array}{c}\text { Autochthonous } \\
\text { case rate }\end{array}$ \\
\hline 1971 & 5 & 0.2 & 1981 & 5 & 0.1 \\
1972 & 5 & 0.4 & 1982 & 5 & 0.1 \\
1973 & 4 & 0.1 & 1983 & 6 & 0.1 \\
1974 & 5 & 0.3 & 1984 & 7 & 0.2 \\
1975 & 6 & 0.2 & 1985 & 8 & 0.3 \\
1976 & 5 & 0.1 & 1986 & 9 & 0.2 \\
1977 & 6 & 0.7 & 1987 & 10 & 0.1 \\
1978 & 5 & 0.1 & 1988 & 8 & 0.1 \\
1979 & 5 & 0.2 & 1989 & 8 & 0.1 \\
1980 & 5 & 0.2 & 1990 & 6 & 0.1
\end{tabular}

Source: Population data were obtained from the Brazilian Geographic and Statistical Institute.

a Case data for the period 1971-1974 were provided by the Superintendency of Environmental Sanitation, while those for the period 1975-1990 were provided by the Superintendency for Control of Endemic Diseases. nature, both in São Paulo State and in Brazil generally. Nationally, nearly all the malaria cases were accounted for by a relatively small number of municipalities in the Amazon region. More specifically, as of 1990 roughly $85 \%$ of all cases came from only 79 municipalities. São Paulo and Paraná were the most vulnerable states, as most of the cases traveling out of the Amazon region ended up in these states, and it was there that most of them were eventually diagnosed. Within São Paulo State, 16 municipalities had active, naturally occurring transmission as of 1990, while 224 municipalities scattered throughout the state recorded imported cases-clearly indicating a spread of sources of infection.

During this 20-year period there was an urgent need to ensure that the chain of transmission would remain broken, reduce residual foci, and control any newly-detected foci in a timely manner. Control activities were delegated from the municipalities to each individual town or village. Such activities, involving mainly epidemiologic surveillance, concentrated on the most vulnerable groups and territories.

Although keeping the population of the state free of the disease appeared relatively easy under the conditions prevailing at the time, two difficulties became immediately apparent. On the one hand, the ongoing influx of imported cases dictated a need for quick and timely surveillance; on the other, the authorities demonstrated relative lack of interest in providing the resources needed to control a problem that was merely a threat rather than a reality. Nevertheless, the structure of the state program appeared efficacious-inasmuch as the program prevented reestablishment of transmission, controlled residual foci, and prevented creation of new foci. In addition, it had permitted investigation and control of unforeseen and hard-tomanage situations such as the appearance of cases in users of injected drugs.

Slowly, over the course of this period, malaria ceased to be a danger for the population at large and began to affect mainly certain groups, i.e., those whose work required them to 
travel to endemic areas or those whose personal behavior, such as drug use or outdoor recreational activities, exposed them to the disease.

In general, experience has shown that once transmission has been interrupted successfully, the disease rarely reestablishes itself in areas undergoing a satisfactory process of socioeconomic development. The fear that transmission's persistence in neighboring areas would diminish the effectiveness of control initiatives is not supported by the trends observed in recent decades.

\section{REVIEW OF THE ERADICATION CAMPAIGN IN THE 1990s}

Since the mid-1970s, deterioration of the epidemiologic situation prevailing in underdeveloped countries has reduced belief in the chances for shortterm malaria eradication and has led WHO to recommend a review of the campaign-based strategy. Initially, the so-called "resurgence" of malaria was attributed to technical and logistic deficiencies in implementing eradication campaigns, to reduced financial resources devoted to the effort, and to a certain weakening of the political will to eradicate the disease. Subsequently, the problem was attributed to an overly automatic application of the campaign-based strategy, one that failed to employ knowledge of local epidemiologic profiles (25-27).

The belief that malaria was once again on the upswing as a result of a poorly implemented strategy led to an effort to correct deficiencies in the eradication campaign without changing its essential characteristics. Little by little, however, the persistently rising incidence altered prevailing malaria control concepts and gave rise to what became known as the "focal" theory. This theory was based on a reawakened realization that the disease has extremely heterogeneous manifestations in different epidemiologic contexts and upon attempts to understand why in certain foci efforts to interrupt transmission had been unsuccessful.
Instead of emphasizing the "failure" of eradication efforts, a positive attitude employing the focal concept was adopted. The immediate consequences of this new approach were a return to the old concept of epidemiologic stratification, diversification of control techniques and activities, and recognition of the importance that the organizational model of primary care has in providing care for clinical cases.

The focal theory made it impossible to reduce the malaria "equation" to the overly simplistic binomial of the vector and the positive slide, because it depended on relationships rooted in the concept of epidemiologic stratification. Indeed, it proposed this latter concept as a tool for identifying areas of homogeneous risk and guiding application of technologies that were appropriate, scientifically adequate, and socially acceptable and accessible (28-30). This focal model was criticized on both conceptual and operational grounds. Conceptually, the main objection was to the priority assigned spatial categories, since stratification was seen as territorial, without regard to changes produced over time. Operationally, critics pointed to the limitations inherent in the databases created in accordance with geopolitical divisions where homogeneous epidemiologic situations were rarely found in the case of malaria, and to the need for conducting long and costly information surveys when suitable records were not available $(28,31)$.

As a result of these criticisms, it was proposed that risk strata be abandoned and that paradigms or models be adopted wherein ecologic and social determining factors would be expressed in terms of "ideal types" useful for developing control patterns adapted to various epidemiologic situations $(32,33)$. However, emphasis on local characteristics was even more notable in the "microepidemiologic" approaches that appeared toward the end of the 1980s-approaches based on anthropologic study of individuals and family groups - as a result of which the unit of analysis was reduced to the individuals exposed to risk (34).
In the course of all this the eradication concept was gradually abandoned and replaced by the risk approach, which initially was applied to various population strata, subsequently to paradigmatic epidemiologic situations, and finally to households and individuals. During this process, the general was replaced by the specific and population-wide public health practices gave way to preventive practices directed at protecting the individual.

International guidelines for controlling the disease were radically modified during a 1992 ministerial conference sponsored by WHO in Amsterdam (35). According to guidelines approved by the participating health ministers, malaria control was to consist of three groups of activities. The first, termed "disease management," included all matters involving case diagnosis and treatment. In this area, governments were responsible for ensuring that appropriate means were available to provide infected individuals with correct diagnosis and appropriate treatment. The aim was not to eliminate sources of infection but rather to reduce malaria morbidity and mortality. Activities oriented toward active case searches were to be suspended and the task of "disease management" was to be assigned to primary health care facilities. The second group of activities, aimed at "disease prevention," included measures for individual protection, chemoprophylaxis, immunization, and domiciliary vector control. The focus of control activities was shifted away from the environment and protection of potential hosts and toward individuals and their "at-risk behaviors." The third group of activities, designated "prevention and control of epidemics," encompassed traditional epidemiologic surveillance activities as well as collective interventionsprimary responsibility for which continued to rest with the state.

The decision to make individuals responsible for their own protection, while leaving the programs responsible for ensuring the resources needed to diagnose and treat cases, opened the door to a possible rise in the exist- 
ing lack of equity (36). Collective activities were applied to all individuals, regardless of their susceptibility to contracting the disease and regardless of their individual behavior; such activities were more oriented toward society as a whole than toward the individual. In contrast, control activities with an individual focus affected each of the individuals implementing them; and so the conditions in which the disease occurred were now dependent on the behavior of the individual. In this way, the lack of equity prevailing in the organization of society tended to replicate itself in the control structure, since individuals in marginal social strata, who tended to be at greatest risk for becoming infected, also found it more difficult to adopt the recommended protective measures or seek the services of health care centers.

In sum, it appears that when the new control strategy was implemented, the goal of placing scientific and technical advances within the reach of all was abandoned. It was taken for granted that socioeconomic inequalities existed and that they could not be corrected with technical interventions. The lack of malaria control in developing countries did not constitute a threat for developed countries; and, accordingly, from the perspective of the developed countries a worldwide initiative to address the problem was no longer necessary. Each country should therefore weigh its needs in the light of its own potential for action, resorting to technical and scientific measures that would facilitate its economic development.

This pragmatism and surrender to the difficulties of extending control to areas where conditions unfavorable for socioeconomic development prevailed meshed perfectly with the "new world order" in which the "inept" who were unable to accumulate capital for their own benefit were gradually left by the wayside, thus aggravating profound social inequalities and hard-toresolve problems. In this new order of things, only individuals with "romantic" and "utopian" vision could still expect a future in which all would be able to coexist in complete harmony.

\section{REFERENCES}

1. Fundação SEADE/USP. Atlas de população do Estado de São Paulo. São Paulo: Fundação SEADE/USP; 1992.

2. Monbeig P. Pioneiros e fazendeiros de São Paulo. São Paulo: Editora HUCITEC/Polis; 1984.

3. Costa Filho A. Relatório do período 1933-1937. São Paulo: Inspetoria de Prophilaxia do Impaludismo; 1937.

4. Ayrosa Galvão AL, Lane J. Notas sobre os Nyssorhincus de São Paulo. Rev Biol Hig 1937; 9:37-45.

5. Correa RR. Da infecção natural pela plasmodiose malárica do A. (K.) cruzi. Fol Clin Biol 1943;15:23-32.

6. Correa RR, Ramos AS, Rachou R. Anofelismo e malária em algumas represas em São Paulo. Fol Clin Biol 1943;15:33-43.

7. Correa RR, Ramos AS. Os anofelinos da ilha de Santo Amaro. Arq Hig Saude Publica 1944; 9:7-16.

8. Correa RR, Lima FO, Ramos AS. Os anofelinos do subgênero kertzsia: sua relação com a malária no Estado de São Paulo. Dusenia 1950; 1:203-214.

9. Correa RR, Lima FO. Antropofilia do A. (N.) albitarsis domesticus, A. (N.) darlingi e Culex fatigans. São Paulo: Serviço de Profilaxia da Malaria; 1990. (Mimeographed document).

10. Russel P. Malaria and society. J Nat Malaria Soc 1951;10:1-7.

11. Unti O. SPM: sua atividade no passado, presente e not futuro. São Paulo: Serviço de Profilaxia da Malaria; 1951. (Mimeographed document).

12. Organisation mondiale de la Santé. Comité d'experts sur le paludisme: rapport sur la première session. Bull World Health Organ 1947; 1:23-32.

13. Organisation mondiale de la Santé. Comité d'experts sur le paludisme: rapport sur la deuxième session. Bull World Health Organ 1948;1:235-279.

14. Cano W. Desequilíbrios regionais e concentração industrial no Brasil 1930-1970. Campinas: Editora Global; 1985

15. Silva LJ. Evolução da doença de Chagas no Estado de São Paulo. [Tesis de doctorado]. Ribeirão Preto: Faculdade de Medicina de Ribeirão Preto, Universidade de São Paulo; 1981.

16. Forattini OP. Entomologia médica. São Paulo: Faculdade de Higiene e Saúde Publica; 1962.

17. Rachou R. Anofelinos do Brasil: comportamento das espécies vetoras da malária. Rev Bras Malariol Doencas Trop 1958;10:145-181.

18. Logan JA. The Sardinian project: an experiment in the eradication of an indigenous malarious vector. Baltimore: Johns Hopkins University Press; 1953.

19. World Health Organization. Expert Committee on Malaria: sixth report. Geneva: WHO; 1956. (Technical report series, 123.)

20. Marques AC. Migrações internas e grandes endemias. Rev Bras Malariol Doencas Trop 1979; 31:137-158.

21. Sabroza PC. A malária no Brasil. Cadernos Saude Publica 1985;1:71-111.

22. Marques AC, Pinheiro EA, Motta EGF. Fatores que dificultam o controle da malária na região amazônica. São Paulo: Superintendência de Controle de Endemias; 1977. (Mimeographed document).

23. Shiang LS. Malária em usuários de drogas de administração endovenosa associado à soropositividade para HIV. Rev Saude Publica 1991;25:17-22.

24. Barata LCB, Andriguette MTM, Cortés MC, Meneguetti C. Sutra de malária induced em usuários de drogas injetáveis. Rev Saude Publica 1993;29:9-14.
25. Bruce-Chwatt LJ. Malaria control at the crossroads: where do we go from here? Mem Inst Oswaldo Cruz 1986;81(suppl 2):1-8.

26. Lepes T. Malaria: a global health problem. Geneva: World Health Organization; 1981. (Document WHO/MAL 81.749).

27. Nájera J. A global analysis of malaria eradication in relation to the development of primary health care. Geneva: World Health Organization; 1986. (Document WHO/MAL 86.1025).

28. Beales PF, Nájera J. A reconsideration of the tactical variants for malaria control in the light of experience in their utilization. Geneva: World Health Organization; 1986. (Document WHO/MAL 86.1027).

29. Orlov VS, Semashko IN. Malaria stratification as a tool in developing the strategy and tactics for modern long-term malaria control programmes. Geneva: World Health Organization; 1986. (Document WHO/MAL 86.1029).

30. Orlov VS, Semashko IN. Malaria stratification of territories and its practical implications. Geneva: World Health Organization; 1986. (Document WHO/MAL 86.1032).

31. Rubio-Palys Y. Malaria in the Americas: ecological/epidemiological paradigms. São Paulo: Superintendência de Controle de Endemias; 1992. (Mimeographed document).

32. Nájera J, Liese B, Hammer JS. Health sector priorities review: malaria. Washington, DC: World Health Organization, World Bank; 1991.

33. World Health Organization. Malaria control, an attainable goal: a strategy for malaria control. Paper presented at the Ministerial Conference on Malaria, Interregional Meeting for Africa, Brazzaville, Congo, October 21-25, 1991.

34. Greenwood BM. The microepidemiology of malaria and its importance to malaria control. Trans $R$ Soc Trop Med Hyg 1989;83(suppl): $25-29$. 
35. Organización Mundial de la Salud. Estrategia mundial de la lucha contra el paludismo. Paper presented at the Ministerial Conference, Amsterdam, The Netherlands, 1992.
36. Bradley DJ. Malaria: whence and whither? In: Taegett GAT. Malaria: waiting for the vaccine. London: London School of Hygiene and Tropical Medicine; 1991.
Manuscript received on 24 May 1995. Revised version accepted for publication on 30 April 1996.

RESUMEN El aumento de la incidencia de malaria en varios países del mundo a partir de los años setenta, cuando parecía que estaba a punto de erradicarse la enfermedad, creó una serie de interrogantes y durante algún tiempo los malariólogos y las autoridades de salud pública escasamente comprendían lo que estaba ocurriendo. Con el fin de entender major este proceso, la autora del presente artículo estudió la frecuencia de casos de malaria en São Paulo, Brasil, de 1930 a 1990, procurando examinar los siguientes factores en cada una de las etapas estudiadas: la importancia social de la malaria, las condiciones en que se presentaba la enfermedad, los conocimientos epidemiológicos de la época, los instrumentos técnicos disponibles y las estrategias de control utilizadas, mediante la construcción de modelos tecnológicos. De esta manera se hizo evidente que la presentación de la enfermedad, los conocimientos sobre ella y por consiguiente las formas de hacerle frente sufrieron cambios importantes a lo largo del tiempo. Al final se discuten, a la luz de la investigación, las opciones que existen actualmente para el control de la malaria.

\section{Organización tecnológica del control de la malaria en Să Paulo, Brasil, de 1930 a 1990}

\section{Jornadas Anuales "Progresos en alergia, asma e inmunología"}

Fechas: $\quad 15$ a 18 de agosto de 1998

Lugar: $\quad$ Buenos Aires, Argentina

La Asociación Argentina de Alergia e Inmunología invita a todos los médicos alergólogos y de especialidades afines a reunirse en Buenos Aires en las fechas indicadas, a asistir a la XXII Jornada y a intercambiar conocimientos en alergia e inmunología. Estas Jornadas, que se celebran sin interrupción desde hace 22 años, tienen el propósito de profundizar en la especialidad, promover la educación médica continuada, fomentar la investigación y poner al día a los participantes en cuanto a estrategias para la prevención y el tratamiento de las enfermedades alérgicas.

El programa proyectado incluye, entre otros temas principales, manejo del asma grave y resistente al tratamiento con esteroides, factores del medio ambiente, mecanismos celulares de la inflamación, temas de actualidad en pediatría, uso de nuevos medicamentos, antileucotrienos, avances en inmunoterapia y enfermedades autoinmunitarias. Jean Bousquet, de Francia, G. Walter Canonica, de Italia, Timothy Clark y Olive Page, del Reino Unido, y Allen Kaplan, de los Estados Unidos de América, estarán entre los distinguidos relatores invitados a participar en la sección científica.

Información:

Dra. Anahí Yáñez, Secretaria de Coordinación

Asociación Argentina de Alergia e Inmunología

Moreno 909

1091 Capital Federal

Buenos Aires, Argentina

Correo electrónico: aaaei@houseware.com.ar

Web: http://www.houseware.com.ar/aaai 